\title{
CHK1 Inhibitor PF-477736
}

National Cancer Institute

\section{Source}

National Cancer Institute. CHK1 Inhibitor PF-477736. NCI Thesaurus. Code C68820.

A proprietary compound targeting cell cycle checkpoint kinase 1 (chk1) with potential chemopotentiation activity. Chk1 inhibitor PF-477736 inhibits chk1, an AT P-dependent serine-threonine kinase that is a key component in the DNA replication-monitoring S/G2 checkpoint system. By overriding the last checkpoint defense against DNA damaging agent-induced lethal damage, chk1 inhibitor PF-477736 may potentiate the antitumor efficacy of various chemotherapeutic agents against tumor cells with intrinsic checkpoint defects. 